American Journal of Applied Sciences 6 (3): 424-429, 2009

ISSN 1546-9239

(C) 2009 Science Publications

\title{
Explorations on Web Usability
}

\author{
K.K Teoh, T.S. Ong, P.W. Lim, Rachel P.Y. Liong and C.Y. Yap \\ Faculty of Information Science and Technology \\ Multimedia University, Jln Ayer Keroh Lama \\ 75450 Melaka, Malaysia
}

\begin{abstract}
The area of web usability has long intrigued researchers. It has been widely accepted that for a website to be successful, the level of usability has to be high. The reason is because of poorly designed website. While many web designers largely fall on their prior experience to tell if a web site design is good or bad, there is a need to be able to provide clear methodology to do so ${ }^{[2,3]}$. An article by Goldsborough which quoted Nielson, reported that while many web designers think their websites are important, generally it is users who will determine the relevance of these websites. In this paper, we discuss the methodology of usability and the survey conducted for the webpage that we have done.
\end{abstract}

Key words: Web usability, consistency, interactivity, accessibility, content

\section{INTRODUCTION}

HCI has developed to become an important area of computer science. Generally, HCI refers to a study of communication between human and computer which draws from supporting knowledge on both human and machine. Denning in a report for the $\mathrm{ACM}^{[5,6]}$ defined human computer interaction as the systematic study of algorithmic processes that describe and transform information: their theory, analysis, design efficiency, implementation and application and the efficient coordination of action and transfer of information between humans and machines via various human-like sensors and motors and with information structures that reflect human conceptualizations ${ }^{[6]}$.

While there are a variety of approaches in human computer interaction, we are particularly interested in usability. The ISO $9241-11^{[7]}$ referred to usability as the extent to which a product can be used by specified users to achieve specified goals with effectiveness, efficiency and satisfaction in a specified context of use while ISO 13407 mentions that Human-centered design is characterised by: the active involvement of users and a clear understanding of user and task requirements; an appropriate allocation of function between users and technology; the iteration of design solutions; multidisciplinary design. Denning ${ }^{[6]}$ also suggests that cognitive psychology and risk analysis be incorporated into HCI studies.
Hence, we summarize that usability generally encompasses studies of products as its specific use. Studies of usability should include understanding of relationship between users (cognitive and psychological), task requirements, technology involved (including the risks).

A study ${ }^{[8]}$ indicated that more $50 \%$ of programming and design are spent on user interface, indicating how important usability studies are. With the introduction of the Internet, it has become increasingly more important to understand usability issues dealing with the web ${ }^{[9]}$. Hence, various studies of late has concentrated on web usability ${ }^{[10-13]}$.

To understand the variables influencing website usability, we have attempted to conduct some usability testing on a website. The website which was identified for the purpose is for the faculty's Biometrics and Bioinformatics (CBB) Website.

Generally, usability testing hopes to improve the performance and experience of the web users, leading to a better system. This can be achieved by identifying usability issues and finding solutions to solving them.

Usability Framework: In order to conduct our research, we have analyzed a few factors namely: Screen Appearance, Consistency, Accessibility, Navigation, Media Use, Interactivity and Content. The seven factors are explained below.

Screen appearance would indicate the design of the website in terms of the on-screen information.

Corresponding Author: K.K Teoh, T. S. Ong, Faculty of Information Science and Technology Multimedia University Jln Ayer Keroh Lama 75450 Melaka, Malaysia 


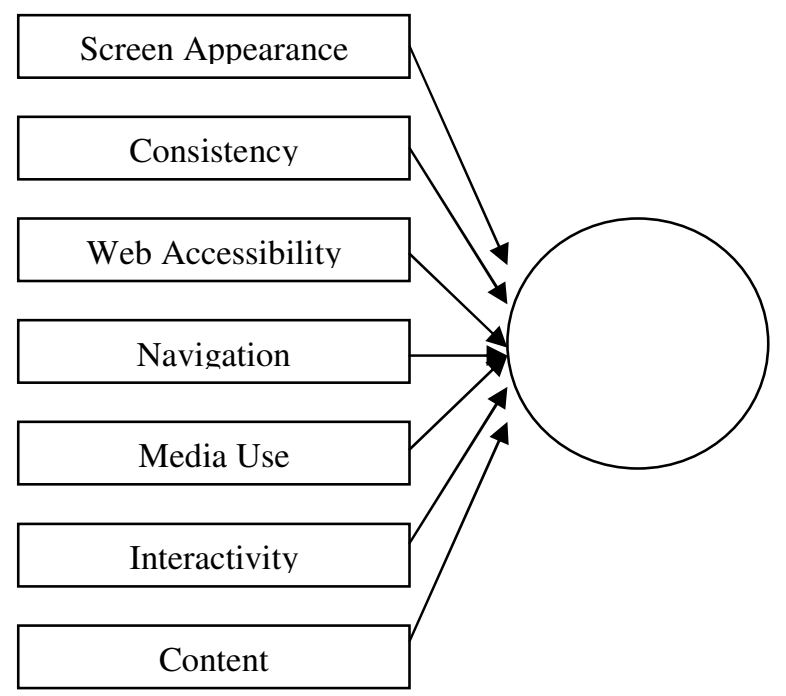

Fig. 1: Usability Framework

Consistency refers to the uniformity of design, taking into considerations graphics, placement and observable schemes and patterns. Web accessibility would refer the ability to access the web site from different browser platforms, either software or hardware related. Navigation would take into consideration the "hypermovements" between pages and between websites. Media use refers to the use of multimedia i.e., text, graphics, video, animation, etc. Interactivity refers to the level of communication of the website in the form of contact information, enquiries, forum and so on. Content refers to the information and general gist of the website.

According to the US Department of Health and Human Services ${ }^{[14]}$, usability testing would refer to collecting data on the paths users take to do tasks, the errors they make, when and where they are confused or frustrated, how fast they do task, whether they succeed in doing the task and how satisfied they are with the experience. Hence we have decided to allow participants to try the websites and then gather feedback from the users at the end of the experiment.

Case Study: The Center of Biometrics and Bioinformatics is basically one of the research centers in Multimedia University. It is made up of a group of approximately 40 research and academic staff including post graduate students. CBB aims to focus and coordinate research efforts in the area of biometrics and bioinformatics within the university.
In this respect, a efficient website for $\mathrm{CBB}$ is essential to ensure that the members are able to access relevant and needed information easily and effortlessly. Generally, the goals of the website project are:

- To improve the design and deployment of the current website by applying the seven usability criteria mentioned earlier

- To introduce greater interactivity between users and website in order to achieve maximum efficiency

- To ensure that cost and time is kept in check during the design and development of the website by applying the usability factors

In general, the project will begin with the design of a questionnaire based on the 7 criteria (as discussed earlier) on web usability. A group sample users have been identified and the questionnaire was distributed to obtain their feedback. Once the survey data has been collected, it is analyzed using SPSS. We discuss this in length in the next section. The results of the analysis were then used to decide on the design of the website. Ultimately, the website was built with some major modifications from its original design and it now comes with functions such as user login and registration, a feedback page, an FAQ page, an internal search engine and other features.

\section{MATERIAL AND METHOD}

Quantitative research methodologies have been employed in this research. It involves a set of survey which was distributed to 40 lecturers, researchers, postgraduate students, research officers and undergraduate students within the university.

As this survey is meant as an exploration and due to the limited number of members within the center, we have decided on a smaller size sample. While the confidence of the results based on smaller size sample has often been debated, some researchers ${ }^{[15-17]}$ on usability have argued that it is not necessary to use research sample which are too huge unless necessary.

The items used are generally 3 point Likert scale and ranking questions.

We have opted to use SPSS as the tool to analyze our data as it is commonly used and accepted by research community and because it is capable of performing all the analyses which we require.

The smaller sample size of our study allows us to use small, non-parametric tests and descriptive statistical reports. The use of descriptive report would 
Am. J. Applied Sci., 6 (3): 424-429, 2009

\begin{tabular}{|l|c|}
\hline & Level_of_satisfaction_A \\
\hline Chi-Square & .306 \\
df & 4 \\
Asymp. Sig. & .989 \\
\hline
\end{tabular}

Fig 2: Kruskal Wallis Test for significant difference of satisfaction level (Screen Appearance)

enable us to explore the more prominent aspects of the data. We would be using Kruskall-Wallis, $\mathrm{H}$ statistics $^{[18,19]}$, Friedman's Test, One way ANOVA and Cochran's Q Test for non-parametric testing.

Kruskall Wallis ${ }^{[18,19]}$ is a non-parametric test to analyze the possible differences between 3 or more independent groups and it's possible conditions. In this case, the mean sum is computed for each group followed by the mean rank sum. We will use this test to analyze the satisfaction level of users for each usability factor which we have identified namely: Screen Appearance, Consistency, Accessibility, Navigation, Media Use, Interactivity and Content. Following this, a one way ANOVA test to check the criteria with the highest mean difference value is conducted. This would refer to the criteria that vary significantly from others. Friedman test ${ }^{[20]}$ is basically used to test null hypothesis different treatment effects are equal for data in a two-way layout. Friedman's test provides a different option to ANOVA, especially when assumed normality or equity of variance is not found.

Another non-parametric test we use is Cochran's Q Test. It is used when variables are dichotomous in order to test similar distributions among several dependent samples. Essentially, Cochran's Q Test would test the null hypothesis that the dependent samples have the same mean on a dichotomous variable.

Survey Analysis: Kruskal-Wallis Test: Assume that for all the 7 criterias, the null hypothesis, $\mathrm{H}_{0}$ and the alternative hypothesis, $\mathrm{H}_{1}$ is set as shown below.

$\mathrm{H}_{0}=$ There is no significant difference of satisfaction level among the sub criterion.

$\mathrm{H}_{1}=$ There is significant difference of satisfaction level among the sub criterion.

$*$ Set the p-value to 0.05 .

Kruskal Wallis Test for significant difference of satisfaction level (Screen Appearance)

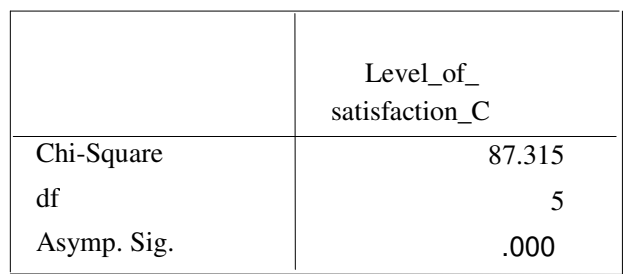

Fig.3: Kruskal Wallis Test for significant difference of satisfaction level (Accessibility)

\begin{tabular}{ll}
\hline & Mean Rank \\
\hline Screen Appearance & 4.08 \\
Consistency & 5.24 \\
Accessibility & 5.08 \\
Navigation & 4.03 \\
Media Use & 3.90 \\
Interactivity & 3.10 \\
Content & 2.59 \\
\hline
\end{tabular}

Fig.4: Friedman's Test

Because the asymp sig value (0.989) is greater than the p-value of 0.05 , we conclude that there is no significance difference of satisfaction level among the sub criteria under Screen Appearance.

*The testing results for the other 4 main web usability criteria (Consistency, Navigation, Media Use and Interactivity) are similar to the above. In short, there is no significance difference of satisfaction level and the respondents are satisfied with all the sub criteria.

Kruskal Wallis Test for significant difference of satisfaction level (Accessibility)

Since the asymp sig value (0.000) is less than the $\mathrm{p}$-value of 0.05 , we conclude that there is significance difference of satisfaction level among the sub criteria under Accessibility section. At least one of the sub criteria differs in terms of satisfaction level.

*The testing results for the Content criteria are similar to the above where the asymp sig value is less than $p$-value of 0.05 .

In order to find out which of the criteria differ the most, we have performed a One Way ANOVA Test. Based on the ANOVA test result, we found out that both sub criteria all browser and different version are the most satisfied sub criterions. Whereas the local search engines sub criteria is the one with the least satisfied results. It has scored the highest mean difference value of 2.200. Friedman's Test: For the question that asked which of the seven web usability 
Am. J. Applied Sci., 6 (3): 424-429, 2009

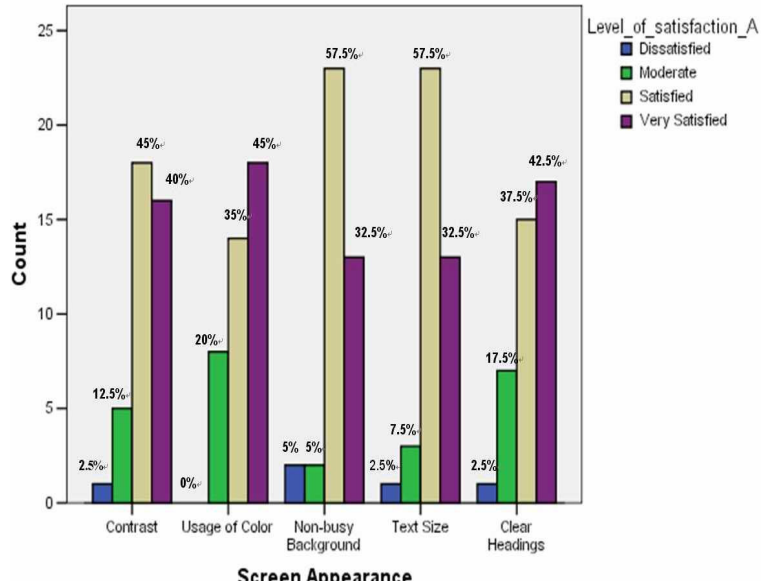

Fig. 5: Percentage of satisfaction for sub criteria in Screen Appearance

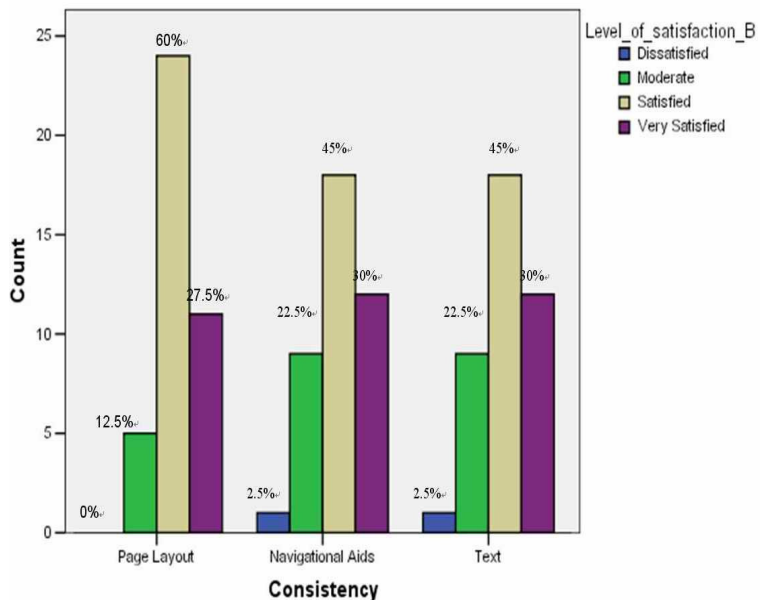

Fig. 6: Percentage of satisfaction for sub criteria in Consistency

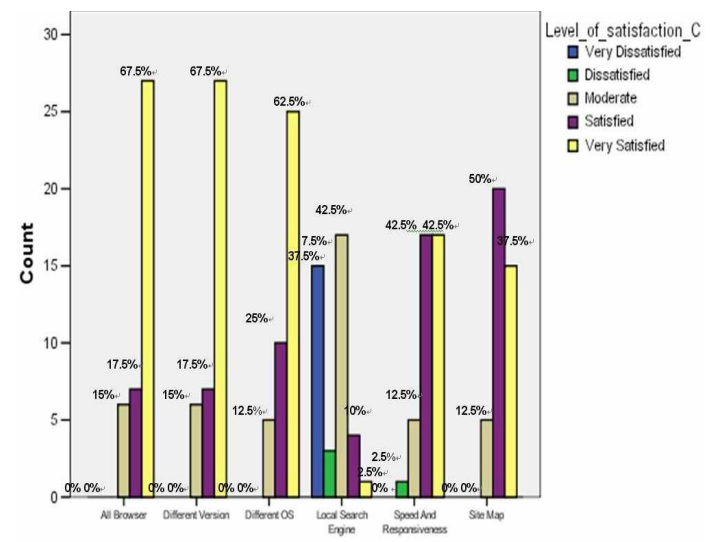

Fig.7: Percentage of satisfaction for sub criteria in Accessibility

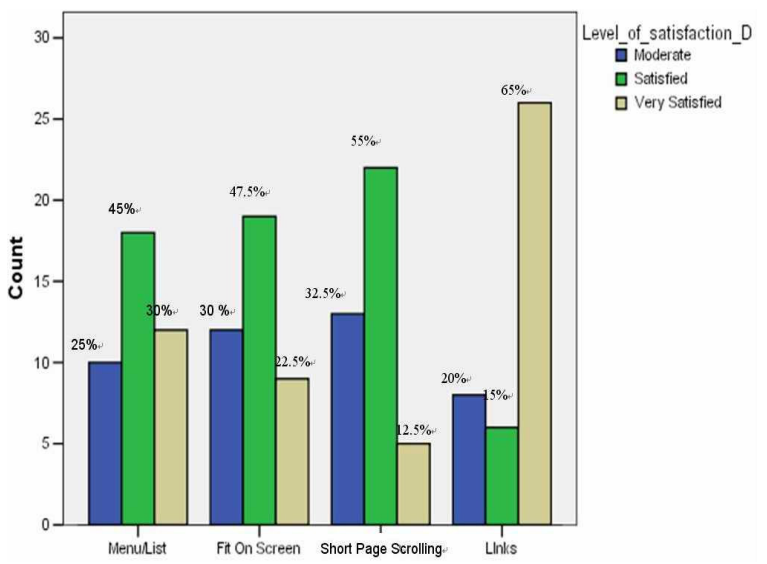

Fig. 8: Percentage of satisfaction for sub criteria in Navigation

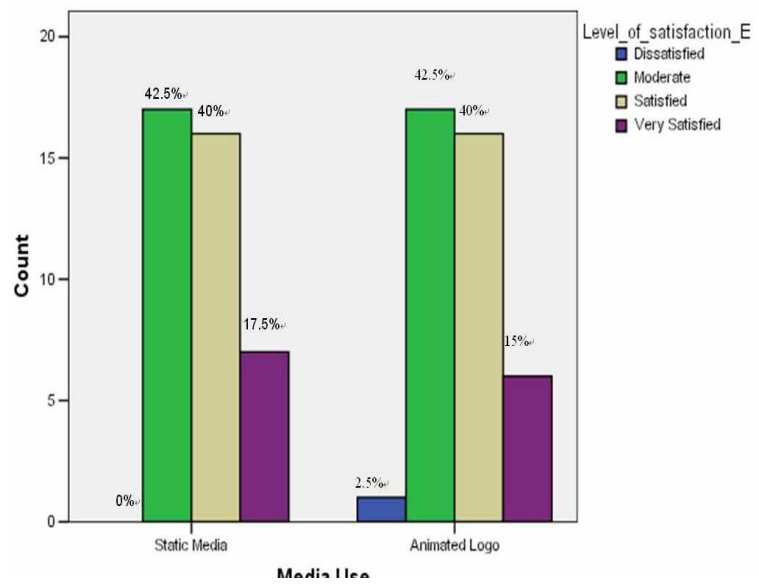

Fig.9: Percentage of satisfaction for sub criteria in Media Use

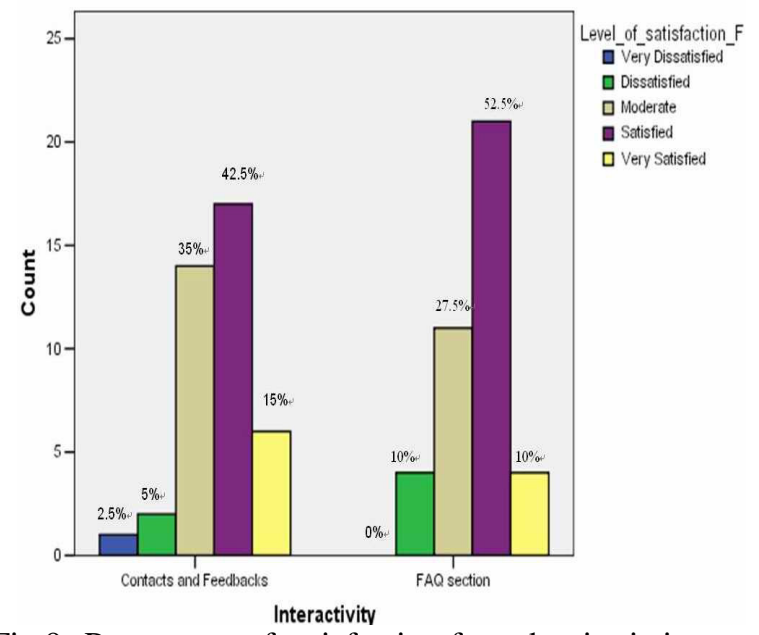

Fig.9 Percentage of satisfaction for sub criteria in Media Use 


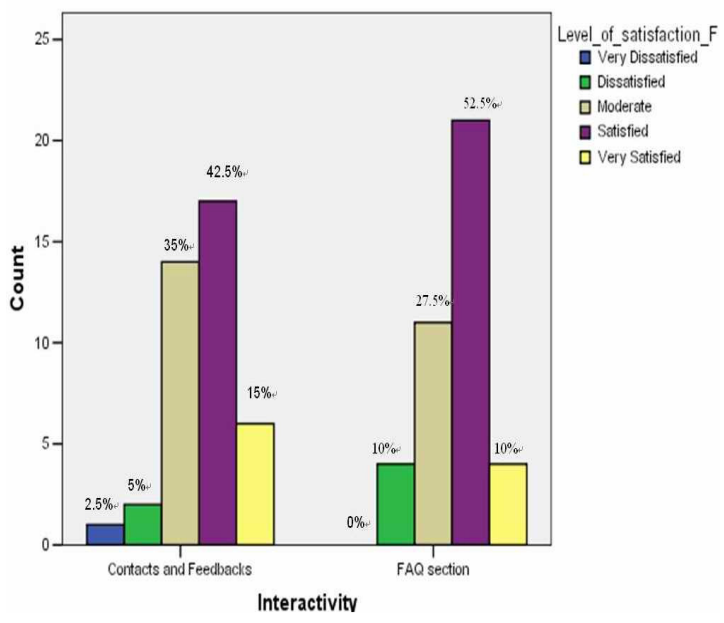

Fig.10: Percentage of satisfaction for sub criteria in Interactivity

\begin{tabular}{|c|c|c|c|c|c|c|c|}
\hline & & \multicolumn{5}{|c|}{ Level_of_satisfaction_G } & \multirow[b]{2}{*}{ Total } \\
\hline & & $\begin{array}{c}\text { Very } \\
\text { Dissatisfie }\end{array}$ & $\begin{array}{l}\text { Dissat } \\
\text { isfied }\end{array}$ & $\begin{array}{l}\text { Moder } \\
\text { ate }\end{array}$ & $\begin{array}{c}\text { Satisf } \\
\text { ied }\end{array}$ & $\begin{array}{c}\text { Very } \\
\text { Satisfiec }\end{array}$ & \\
\hline Content N & Member List & 0 & 0 & 6 & 21 & 13 & 40 \\
\hline & $\begin{array}{l}\text { Profile/About } \\
\text { Us }\end{array}$ & 1 & 4 & 10 & 13 & 12 & 40 \\
\hline & Bulletin & 3 & 6 & 22 & 9 & 0 & 40 \\
\hline & FAQ's & 0 & 2 & 17 & 12 & 9 & 40 \\
\hline & Feedback & 0 & 2 & 15 & 13 & 10 & 40 \\
\hline & Links & 0 & 2 & 5 & 21 & 12 & 40 \\
\hline & Publication & 0 & 0 & 11 & 11 & 18 & 40 \\
\hline & Objectives & 0 & 5 & 11 & 13 & 11 & 40 \\
\hline & Functions & 0 & 1 & 18 & 16 & 5 & 40 \\
\hline & Projects & 1 & 0 & 14 & 13 & 12 & 40 \\
\hline & $\begin{array}{l}\text { Area of } \\
\text { interests }\end{array}$ & 0 & 0 & 13 & 16 & 11 & 40 \\
\hline & $\begin{array}{l}\text { Documents } \\
\text { Division }\end{array}$ & 0 & 1 & 8 & 11 & 20 & 40 \\
\hline & Mission & 0 & 2 & 12 & 23 & 3 & 40 \\
\hline & $\begin{array}{l}\text { Contact } \\
\text { Information }\end{array}$ & 0 & 1 & 8 & 22 & 9 & 40 \\
\hline & $\begin{array}{l}\text { Background } \\
\text { Information }\end{array}$ & 0 & 2 & 9 & 23 & 6 & 40 \\
\hline & $\begin{array}{l}\text { Statistical } \\
\text { Counter }\end{array}$ & 1 & 6 & 24 & 9 & 0 & 40 \\
\hline & $\begin{array}{l}\text { Upload and } \\
\text { Download }\end{array}$ & 1 & 6 & 21 & 12 & 0 & 40 \\
\hline & $\begin{array}{l}\text { Allocation of } \\
\text { date and time }\end{array}$ & 2 & 3 & 15 & 17 & 3 & 40 \\
\hline & Site Map & 0 & 0 & 4 & 20 & 16 & 40 \\
\hline & $\begin{array}{l}\text { Information } \\
\text { Accuracy }\end{array}$ & 0 & 0 & 12 & 20 & 8 & 40 \\
\hline & $\begin{array}{l}\text { Information } \\
\text { Updated }\end{array}$ & 2 & 5 & 7 & 17 & 9 & 40 \\
\hline Total & & 11 & 48 & 262 & 332 & 187 & 840 \\
\hline
\end{tabular}

Fig.11: Total count of satisfaction level for sub criteria in Content

criteria has achieved its best level of conformance in the enhanced CBB website, Friedman's Test was chosen to show the ranking for the results.

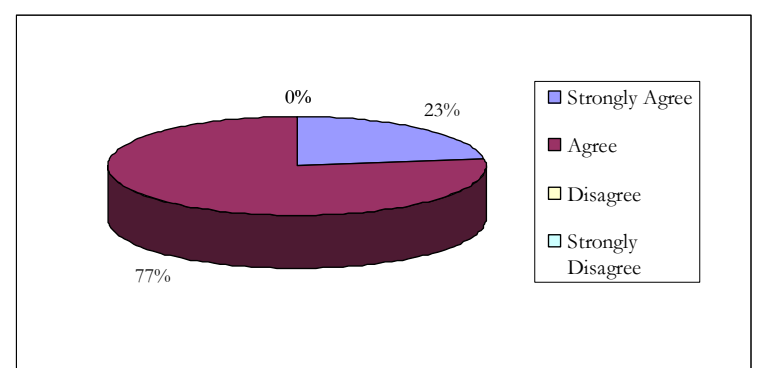

Fig. 12: Pie chart showing that the enhanced CBB website is found to be more effective and efficient over the existing system.

Based on the Fig. 4-10 we can conclude for the ranking of the 7 criteria based on the mean rank calculated. The criterion with the most important is Content (2.59) and the least important is Consistency (5.24).

Fig.11 shows that the sub criterion document division has the highest total of very satisfied level, 20, if compared to the other sub criteria under the Content section, The sub criteria that is less satisfied under the Content section is the Bulletin sub criteria with the total of 9 counts of satisfied respondents.

\section{RESULT AND DISCUSSION}

Pie chart showing that the enhanced $\mathrm{CBB}$ website is found to be more effective and efficient over the existing system.

The majority of respondents $(77 \%)$ agree the enhanced $\mathrm{CBB}$ website is more effective and efficient in terms of all criteria (navigation, screen appearance etc) over the existing system, while $23 \%$ of the respondents strongly agreed that the enhanced $\mathrm{CBB}$ website is becoming more convenient and useful compared to the existing system.

From the previous analysis, we found that the criterion with the most significant importance is Content (2.59), Interactivity (3.10), Media Use (3.90), Navigation (4.03), Screen Appearance (4.08), Accessibility (5.08) and the least important is Consistency (5.24).

The respondents' selection of multiple criteria for the website's best level of conformance in the enhanced CBB website is also interesting. From the statistical testing, Screen Appearance achieved the best level of conformance with highest mean value 0.85 , followed by Content (0.70), Consistency (0.68), Navigation (0.43), Media Use (0.40), Interactivity $(0.25)$ and the least is Accessibility (0.20). 
Besides that, we have obtained comments and feedback from the use of an open ended question. Most of the respondents suggested adding more useful links to let user to obtain useful information. There are some respondents who had also hoped to download useful information from the CBB website such as project paper and journals and so on. There are some respondents who suggested that $\mathrm{CBB}$ improves the stability and the accessibility of the website. Others also suggested that the CBB website should viewed appropriately in different browser and fixing the different resolutions in different computers.

Last but not least, there are some positive feedbacks from respondents such as a pleasant design of interface, consistent page layout and proper navigation. Most of the respondents agree that CBB's website is has improved after significant changes.

\section{CONCLUSION}

We have researched the different web usability elements needed to create a successful website. Generally, the elements which are deemed most important are: Screen Appearance, Content, Consistency, Navigation, Media Use, Interactivity and Accessibility with Content being the most important determinant. Future research may include the use of $3 \mathrm{D}$ and real time interaction to analyze usability issues.

\section{REFERENCES}

1. Tauscher, L. and S. Greenberg, 1997. How people revisit web pages: empirical findings and implications for the design of history systems. Int. J. Hum.Compu.Stud. 47.

2. Benyon, D., D. Stone and M. Woodroffe. 1997. Experience with developng multimedia courseware for the World Wide Web: the need for better tools and clear pedagogy. Int. J. Hum.Compu. Stud. 47: p. 197-218.

3. Schneiderman, B., 1997. Designing informationabundant web sites: issues and recommendations. Int. J. Hum.Compu. Stud. 47: p. 5-29.

4. Goldsborough, R., 2001. Survival on the Web Requires Usability, in Business J. (Central New York). p. 8, 2.
5. Denning, P.J. and et. al., 1988. Report on the ACM Task Force on Core of Computer Science, in ACM Press. New York.

6. Denning, P.J.,1999. Computer Science: The Discipline, in Encyclopedia of Computer Science, A. Ralston and D. Hemmendinger, Editors.

7. Resources: About Usability - What is Usability? 2006, Usability Professionals' Association: Bloomingdale.

8. Myers, B.A. and M.B. Rosson. 1992. Survey on User Interface Programming. in Proceedings SIGCHI' 92: Human Factors In Computing Systems. Monterey, C.A.

9. Myers, B., et al., 1996. Strategic Directions in Human-Computer Interaction. ACM Compu. Surveys, 28: p. 793-808.

10. Guell, N., D. Schwabe and P. Vilian. 2000. Modeling Interactions and Navigations in Web Applications. in Proceedings of the ER Workshops on Conceptual Modeling Approaches for eBusiness and the WWW. Springer-Verlag.

11. Kim, E. 1999. A model of effective web. in Proceedings of the the Fifth Americas Conference on Information Systems. Milwaukee, Wisconsin.

12. Ivory, M.Y., R.R. Sinha and M.A. Hearst. Empirically Validated Web Page Design Metrics. in CHI 2001. 2001. Seattle, W.A.

13. Nielsen, J., 2003. Usability 101: Introduction to Usability.

14. Services, U.S.D.o.H.H., Step-by-Step Usability Guide, in Usability.gov.

15. Nielsen, J., 2000. Why you only need to test with 5 users, in Jakob Nielsen's Alertbox.

16. Hopkins, W.G., 1997. Sample Size "On the Fly", in A New View of Statistics.

17. Nielsen, J., 2004. Card Sorting: How many users to test, in Jakob Nielsen's Alertbox.

18. Kruskal, W.H. and W.A. Wallis, 1953. Errata to Use of ranks in one-criterion variance analysis. J. Am Statis. Associ. 48(907-911).

19. Kruskal, W.H. and W.A. Wallis, 1952. Use of ranks in one-criterion variance analysis. J. Am. Statis. Associ,. 47: p. 583-634.

20. Corporation, B., PROPHET StatGuide: Friedman's test. 1997. 